Review

\title{
An investigation of the validity of a homogeneous equilibrium model for different diesel injector nozzles and flow conditions
}

\author{
Ehsanallah Tahmasebi ${ }^{\mathrm{a}, *}$, Tommaso Lucchini ${ }^{\mathrm{a}}$, Gianluca D'Errico ${ }^{\mathrm{a}}$, Angelo Onorati ${ }^{\mathrm{a}}$, Gilles Hardy ${ }^{\mathrm{b}}$ \\ a Internal Combustion Engine Group, Department of Energy, Politecnico di Milano, Italy \\ b FPT Motorenforschung AG, Switzerland
}

\section{A R T I C L E I N F O}

\section{Keywords:}

Nozzle internal flow

Two-phase flow with cavitation

Homogeneous equilibrium mode

Nozzle geometry

Injection pressure

\begin{abstract}
A B S T R A C T
In the present work, a methodology for modeling flow behavior inside the fuel injector holes is applied to a number of cases with different geometries and flow conditions. After assessment of the approach results through various experimental studies looking into the flows behavior inside the diesel nozzles, two series of analyses are defined. In the first study, the effect of inlet pressure is investigated by using a series of different rail pressures in both numerical and experimental tests in a single hole industrial injector. Results show a non-cavitating flow and an approximately linear increase of the velocity, turbulence kinetic energy, and turbulence dissipation energy with the increase of pressure difference and linear increase of the mass flow rate with the square root of the pressure difference in this nozzle. The second study is related to the effect of hole geometry on injector performance. The effects of entrance edge rounding and the tube conicity factor are investigated by changing these parameters in a series of geometries from an industrial diesel nozzle. Results show that cavitation occurs in the geometries with a sharper edge and low conicity. The role of the cavitation in emerging flow properties is emphasized in the values of the injector discharge factor and the turbulence properties. The results of this work can be used in the simulation of the primary breakup of fuel spray, and this approach is useful for design and optimization of the injectors for industrial sectors.
\end{abstract}

\section{Introduction}

Diesel engines in the modern automotive market are still the best choice for a broad range of applications. Over the past years, advanced injection technologies with higher injection pressure have offered a compromise between emission reduction and fuel consumption which was estimated by Mahr [1] and Baumgarten [2]. A recent report by Morgan et al. [3] has indicated that this approach is still attractive for future diesel engine concepts by using advance techniques as well as injection shaping $[4,5]$. The effects of injector hole geometry in the primary breakup of high-pressure sprays have been emphasized in several investigations. Schmidt and Corradini [6] have shown that cavitation in an injector causes significant initial disturbances that accelerate the breakup process. Cavitating nozzles are expected to generate the most rapid breakup whereas single phase flow relies mostly on turbulent fluctuations produced in them, creating moderate initial disturbances. Desantes et al. [7] have shown that the presence of cavitation in the nozzle exit improves the turbulence intensity in the spray as well as the atomization and mixing process. Their experimental investigations have shown that in inlet/outlet pressure conditions with cavitation inside the nozzle, the fuel jet cone angle increases. Owing to their test conditions, they could not separate the role of cavitation from the effect of fuel pressure. Also fuel temperature could affect the fuel spray characteristics as it considered in several studies like Salvador et al. [8] and Payri et al. [9] work.

As shown by several studies, e.g. Hulkkonen et al. [10]; Salvador et al. [11-13], Wang et al. [14] nozzle characteristics may affect cavitation development. Experimental tests on the behavior of the flow inside the real size cases are difficult, due to their tiny dimensions (on the order of a 100-micron diameter for injector hole), high-pressure gradients, and fast transient processes, thus imposing limitations on some studies such as Winklhofer et al. [15]. Several kinds of research like Pratama et al. [16] in recent years have attempted to use scaled-up experimental geometries, but despite their valuable achievements, scaling does not seem to be entirely applicable to real size injectors. Finding a fast, economical, and reliable numerical tool for estimation of flow behavior inside the injectors, as reflected by Battistoni et al. [17], Bicer and Sou [18], and Brusiani et al.[19], is desired for both academic and industrial purposes. To this end, a Homogeneous Equilibrium Model implemented in the OpenFOAM package [20] has been selected,

\footnotetext{
* Corresponding author.

E-mail address: ehsanallah.tahmasebi@polimi.it (E. Tahmasebi).
} 
and its validity for diesel nozzles has been examined for three different cases. In the first part, experimental tests for a scaled-up two-dimensional geometry are undertaken, and simulations outputs are compared with published experimental results by Pratama et al. [16]. In the second study, this methodology is examined in the simulation of two single hole diesel injectors, with different geometrical characteristics (Spray C and D), from Engine Combustion Network (ECN) [21]. The compatibility of our method with real size injectors in cavitating and non-cavitating regimes is projected in this analysis. The third study focuses on an actual size industrial single nozzle diesel injector. Effects of injection rail pressure on nozzle performance are investigated both numerically and experimentally. Then, the effects of geometrical parameters such as inlet edge rounding and the conicity factor on flow behavior are analyzed.

Nozzle conicity and inlet edge rounding are the two main geometrical parameters on the injector performance. Usually, the amount of conicity of the tube is defined by the conical factor:

$k=\frac{d_{\text {in }}-d_{\text {out }}}{10}$

where $d_{\text {in }}$ and $d_{\text {out }}$ are inlet and outlet diameters of the nozzle.

Cylindrical tubes produce intense cavitation and also increase spray breakup with a significant spray divergence near the outlet. However, axisymmetric conical geometry suppresses cavitation by gradually reducing the effective cross-sectional area of the nozzle [2]. A comparison between a cylindrical layout $(k=0)$ and conventional diesel injectors ( $k=1.1$ to 2 ) shows the influence of this parameter on the nozzle performance, e.g. the amounts of injection rate, fuel velocity, cavitation and turbulence at the outlet as presented by Brusiani et al. [19].

Another important parameter in the fluid behavior inside the injector is the effect of the hole entrance edge. In sharp corners, streamlines cannot follow the sudden changes in geometry direction. Subsequently, the extraction of streamlines, the separation of flow close to the wall, and the generation of strong vorticities become possible. Thus, a suitable condition is available for reducing pressure up to the saturation pressure and the cavitation regime developing. Today, in new diesel injectors, nozzle inlets are usually rounded to improve inflow conditions and remove the unwanted erosion during the injectors working life which gradually changes the spray characteristics. As an example, $k s$ nozzle technology combines the conical and flow-optimized geometries, where the reduction of the cross section area depends on the distribution of the mass flow suppressing any possible cavitation [2].

In the second case study of the present work, the difference of two geometries, specifically their conicity and edge rounding, produce hugely contrasting results. Furthermore, the third study, into realizing the effect of these two parameters, presents an extensive investigation with customized geometries.

For preparing computational grid, blockMesh mesh generation utility, supplied with OpenFOAM is used. The blockMesh utility creates parametric meshes with grading and curved edges. The principle behind this utility is to decompose the domain geometry into a set of 1 or more three dimensional, hexahedral blocks [20].

\section{Theoretical aspects of the method}

Two main approaches are used for modeling two-phase cavitating flows: two fluid flow models treating the liquid and vapor separately on the one hand and continuum flow methods containing a homogeneous mixture of liquid and vapor on the other. In continuum flow methods, an equation of state helps to define the phase changing and cavitation growth. In this work, a homogeneous equilibrium model (HEM) which is suggested by previous works, e.g. Salvador et al. [11]; Schmidt and Corradini [6], is used to capture cavitation growth. The liquid and vapor phases are assumed to be mixed perfectly in each cell while also considering the compressibility of both phases. Likewise, pressure and density are related to each other with a barotropic equation of state as:

$\frac{D \rho}{D t}=\Psi \frac{D p}{D t}$

in which $\Psi$ is the compressibility of the mixture and is defined as the inverse squared sound speed as $\Psi=1 / a^{2}$.

The equation of state should be consistent with the liquid and vapor equations of state when only one phase is present and also at intermediate states when there is a mixture of them. Both phases can be defined with a linear equation of state:

$\rho_{v}=\Psi_{v} \cdot p$

$\rho_{l}=\rho_{l}^{0}+\Psi_{l} \cdot p$

To compute the amount of vapor in the mixture, $\gamma$ is defined as:

$\gamma=\frac{\rho-\rho_{\text {lsat }}}{\rho_{\text {vsat }}-\rho_{\text {lsat }}}$

where $\rho_{v s a t}=\Psi_{v} \cdot p_{s a t}$. It could be observed that in a flow without cavitation $\gamma=0$, whereas for a fully cavitated flow $\gamma=1$. The mixtures density is calculated with Eq. (6), taking into the account vapors amount in the fluid $(\gamma)$ together with a correction term based on the pressure (the mixtures equilibrium equation of state).

$$
\begin{aligned}
\rho= & \gamma \cdot \rho_{v}+(1-\gamma) \cdot \rho_{l}+\Psi\left(p-p_{\text {sat }}\right)=(1-\gamma) \cdot \rho_{l}^{0}+\left[\left(\gamma \cdot \Psi_{v}+(1-\gamma) \cdot \Psi_{l}\right)-\Psi\right] . \\
& p_{\text {sat }}+\Psi \cdot p
\end{aligned}
$$

In Eq. (6), the liquid density at a given temperature condition is defined as $\rho_{l}^{0}=\rho_{\text {lsat }}-\Psi_{l} \cdot p_{\text {sat }}$. As far as the mixtures compressibility is concerned, it is modeled by a simple linear formula:

$\Psi=\gamma \cdot \Psi_{v}+(1-\gamma) \cdot \Psi_{l}$

in which $\Psi_{l}$ is the compressibility of the liquid. Despite this, there are models describing the compressibility of the mixture in a more physical way, as well as studies focusing on compressibility effect [22] but a linear formula is chosen in this work due to the stability and convergence advantages. As for compressibility, it is possible to obtain the viscosity of the mixture through a linear equation:

$\mu=\gamma \cdot \mu_{v}+(1-\gamma) \cdot \mu_{l}$

The methodology used by the solver starts by solving the continuity equation for $\rho$ :

$\frac{\partial \rho}{\partial t}+\nabla(\rho \cdot u)=0$

The value obtained for $\rho$ is used to determine preliminary values for $\gamma$ and $\Psi$ by using Eqs. (5) and (7), and also solving the momentum equation (Eq. (10)) from which the matrix is derived which allows the velocity $u$ to be calculated:

$\frac{\partial(\rho \cdot u)}{\partial t}+\nabla(\rho \cdot u \cdot u)=-\nabla p+\nabla\left(\mu_{f} \cdot \nabla u\right)$

Convection terms in both mass and momentum conservation equations are discretized by using the Gauss theorem with an upwind scheme. This selection provides a stable simulation in the presence of large pressure and density gradients, despite the fact that first-order schemes are known to increase numerical diffusion when the mesh resolution is reduced. Concerning the diffusion terms, the non-orthogonal part of the gradient is included due to the relatively low mesh non-orthogonality for the configurations tested in this work, as recommended by Jasak [23] and Salvador et al. [11]. An iterative PISO algorithm is used to solve for $\mathrm{p}$ and correct the velocity to achieve continuity. The equation solved within the PISO loop is the continuity equation transformed into a pressure equation by using the equation of state (Eq. (6)): 


$$
\frac{\partial(\Psi \cdot p)}{\partial t}-\left(\rho_{l}^{0}+\left(\Psi_{l}-\Psi_{v}\right) \cdot p_{s a t}\right) \cdot \frac{\partial(\gamma)}{\partial t}-p_{s a t} \cdot \frac{\partial \Psi}{\partial t}+\nabla(\rho . u)=0
$$

Once continuity has been reached, the properties $\rho, \gamma$ and $\Psi$ will be updated by use of Eqs. (5)-(7). Respectively these values will be accommodated to solve momentum equation again, and so, repeating the algorithm until reaching desired convergence.

The adjustable time step is limited by both the Courant number and the acoustic Courant number, defined as:

$C o=\max \left(\frac{|u|}{\Delta x}\right) \Delta t$

$C o_{\text {acoustic }}=\max \left(\frac{1}{\sqrt{\Psi} \Delta x}\right) \Delta t$

Selecting the maximum Courant number is a compromise between accuracy of the results and computational costs. As shown in Eq. (12), the time step decreases along with the Courant number reduction, so if this parameter is low, the computational cost can increase considerably. However, if the Courant number is sufficiently high, the accuracy of the numerical outcome provided by the code can get worse. The same consideration is also valid for the acoustic Courant number relating to the propagation of pressure waves in compressible flows as explained by Versteeg and Malalasekera [24].

\subsection{Turbulence modeling}

Due to the presence of solid boundaries and also small dimensions, the flow behavior and turbulence structure are different from free turbulent flows. In particular, the Reynolds number is always very large. This implies that the inertia forces are immensely greater than the viscous forces at these scales. Menter [25] has noticed that results from the $k-\varepsilon$ method are much less sensitive to the arbitrarily assumed values in the free stream, but the near-wall performance is unsatisfactory for boundary layers with adverse pressure gradients. This idea led to a hybrid method called $k \omega-S S T$ using a transformation from the $k-\varepsilon$ model into $k-\omega$ in the near-wall region and the standard model in the fully turbulent region far from the wall. In fact $k \omega-S S T$ model uses the benefits of $k-\varepsilon$ stability in free stream, and removes its weak performance for boundary layers with adverse pressure gradient with shifting to $k-\omega$ model close to the wall and using blending functions. After checking the $k-\varepsilon$ for some simulations and facing difficulties in simulation convergence and stability, due to the performance of the $k \omega-S S T$ method and its benefits for simulating internal flows with high Reynolds numbers and adverse pressure regimes [24], this scheme was selected for the current work. Also previous studies by Bicer et al. [18] and Salvador et al. [11] suggested the same scheme for these working conditions.

\section{Studied geometries and experimental setup}

As discussed before, this work uses three different geometries. In the first study, the capability of the solver in capturing the cavitation regime inside the injector is examined by experimental results from a scaled-up nozzle by Pratama et al. [16]. In the second study, the fuel behavior inside two single hole diesel injectors (Spray C and D) is simulated, and the outcomes are compared with ECN [21] results. After these studies, we focus on an industrial single nozzle diesel injector and compare its results with those from experimental tests. The geometry of the model is provided by the industrial partner with a similar pattern to the experimental case. This analysis is used to check the validity of our approach in different working conditions. Each analysis and its results will be described in the following.

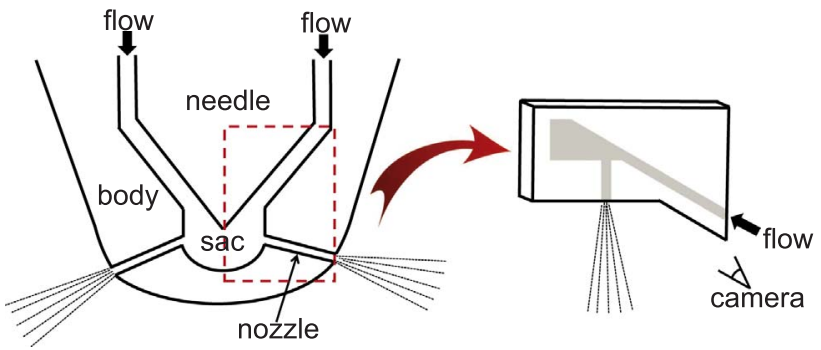

Fig. 1. Left: Scheme of a multi hole injector with a sac area; right: scheme of a scaled-up two-dimensional transparent model for experimental studies.

\subsection{First case study: Scaled-up two-dimensional transparent geometry}

As mentioned earlier, because of the small real size of modern injectors, visualizing the cavitation regime and flow characteristics inside the nozzle is technically difficult. Accordingly, most of the visual studies use scaled-up transparent geometries. Pratama et al. [16] define a series of scaled-up two-dimensional geometries to evaluate the effect of some shape parameters on flow behavior. These scaled-up shapes are intended to maintain some regular features of the injectors and visualize the inflow behavior. Fig. 1 shows a scheme of a multi-hole diesel injector and the scaled-up transparent sector which is defined from the hole and sac area. In the current article, this experimental geometry and its test conditions are used for understanding the capability of our methodology to capture the cavitation regime inside the nozzle. Suitable boundary conditions ought to be imposed to ensure convergence and the accuracy of the simulations. The total pressure boundary condition is set at the inlet with values varying from 2 to 7 bar to find the outlet mean velocities in the range of the experimental results. A fixed 1 bar pressure is used at the outlet. The no-slip condition is imposed at the wall boundaries where wall functions were applied. The thermophysical properties of water in the liquid and vapor phases are used to be consistent with those in the laboratory tests. Table 1 shows the initial conditions for the analysis. The grid properties and wall distance in this table are calculated for a simulation where the inlet pressure equals 6.5 bar.

The studied geometry as well as the quality of the computational grid is shown in Fig. 2. The nozzle is $1 \mathrm{~mm}$ wide, similar to the experimental case.

\subsection{Second case study: Spray $C$ and Spray D from ECN}

To evaluate the validity of our method with experimental tests in real-size nozzles, two geometries are selected as part of a collaboration with the Engine Combustion Network (ECN). Spray C and D are single hole diesel injectors, by standard Spray A from ECN, but mostly more

Table 1

Case setup for a study with an inlet pressure equals to $6.5 \mathrm{bar}$.

\begin{tabular}{cc}
\hline Fluid type & Water @ $T=300 \mathrm{~K}$ \\
\hline Liquid density $\left(\mathrm{kg} \cdot \mathrm{m}^{-3}\right)$ & 1000 \\
Vapor density $\left(\mathrm{kg} \cdot \mathrm{m}^{-3}\right)$ & 0.026 \\
Liquid dynamic viscosity $(\mathrm{Pa} \cdot \mathrm{s})$ & $8 \mathrm{e}-4$ \\
Vapor dynamic viscosity $(\mathrm{Pa} \cdot \mathrm{s})$ & $9 \mathrm{e}-6$ \\
Saturation pressure $(\mathrm{Pa})$ & 4247.05 \\
Liquid compressibility $\left(\mathrm{m}^{-2} \cdot \mathrm{s}^{2}\right)$ & $4.4 \mathrm{e}-7$ \\
Vapor compressibility $\left(\mathrm{m}^{-2} \cdot \mathrm{s}^{2}\right)$ & $4.38 \mathrm{e}-6$ \\
Number of cells & 200,000 \\
Cell type & Structured hexahedral \\
$y^{+}$ & $\sim 1.6$ \\
$\Delta s$ & $1 \mathrm{e}-4$ \\
Re & $\sim 90,000$ \\
Turbulence model & k-omega, SST \\
\hline
\end{tabular}




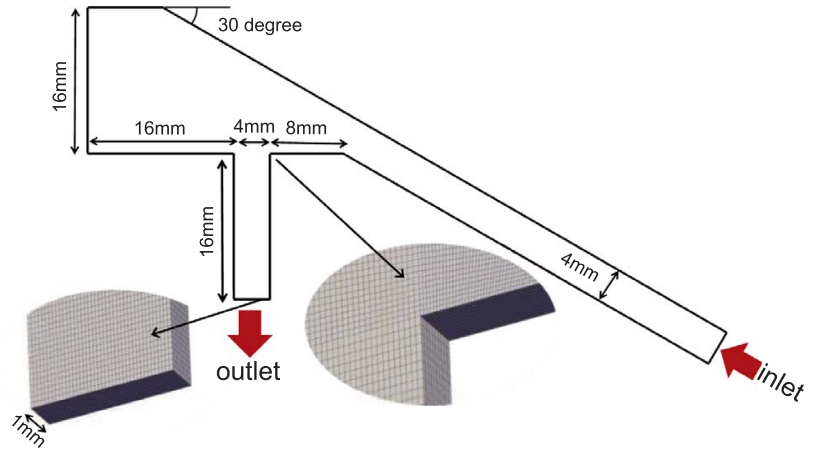

Fig. 2. Simulation geometry and sample of computational mesh.

symmetrical and less affected by manufacturing irregularities [21]. Their larger nominal diameter in comparison to the standard Spray A is defined for future research, with a transparent version of these shapes to be manufactured.

Spray C has a cylindrical hole $(k=0)$ and low edge rounding up to $5 \%$ due to a hydroerosion process. With this geometry and injection pressure, cavitation forming inside the nozzle is expected. On the other hand, Spray D has a conical factor equaling 1.5, and its hole edge has been shaped with the hydroerosion process up to $C_{d}=0.86$ in standard flow conditions as defined by the manufacturer and ECN [21]. $C_{d}$ is the ratio of the actual discharge to the theoretical discharge and is called discharge coefficient. Unlike Spray C, cavitation forms more rarely in this shape. Fig. 3 shows the tomography image of these nozzles along with a graphical comparison of their patterns. For current work, geometries are provided by ECN from measuring manufactured nozzles used for experimental studies. Also simulation is just considering the maximum needle lift condition of the nozzle and transient phases are neglected.

The general specifications of these two geometries provided by ECN [21] are presented in Table 2. For the simulation of the flow inside Sprays C and D, the thermophysical properties of n-Dodecane are retrieved from NIST database [26]. ECN [21] suggests a simplified geometry via removing surface roughness and assumed symmetry. Due to the symmetry of the shapes, simulations were done over a wedge shape portion to reduce computational cost. The initial conditions and overall near wall conditions are presented in Table 3 . The geometry and a sample of the mesh quality close to the nozzle throat are given in Fig. 4.

\subsection{Third case study: Industrial single nozzle injector}

In the third study, an industrial single hole injector with a $k s$ pattern is selected for both experimental and numerical investigations. Laboratory results are used to validate the simulation outcome as well as understanding the effects of inlet and outlet pressure on nozzle performance. A simplified model of this injector is used for simulations.
Table 2

Spray C and D specifications from [21].

\begin{tabular}{ccc}
\hline Parameter & Spray C & Spray D \\
\hline Common rail fuel injector & Bosch 3-22 & Bosch 3-22 \\
Fuel injector nominal diameter & 200 micron & 186 micron \\
Nozzle $k$ factor & 0 & 1.5 \\
Nozzle shaping & $5 \%$ Hydroerosion & Hydroerosion to $C_{d}=0.86$ \\
Flow with 10 MPa pressure & $200 \mathrm{cc} \cdot \mathrm{min}^{-1}$ & $228 \mathrm{cc} \cdot \mathrm{min}^{-1}$ \\
drop & 1 & 1 \\
Number of holes & & 1 \\
\hline
\end{tabular}

Table 3

Case setup for Spray C and D studies.

\begin{tabular}{cc}
\hline Fluid Type & n-Dodecane @ $T=363 \mathrm{~K}$ \\
\hline Inlet Pressure $(\mathrm{MPa})$ & 150 \\
Ambient Pressure $(\mathrm{MPa})$ & 6 \\
Vapor sound speed $\left(\mathrm{m} \cdot \mathrm{s}^{-1}\right)$ & 134 \\
Liquid Sound speed $\left(\mathrm{m} \cdot \mathrm{s}^{-1}\right)$ & 1044 \\
Liquid saturation density $\left(\mathrm{kg} \cdot \mathrm{m}^{-3}\right)$ & 697 \\
Vapor density $\left(\mathrm{kg} \cdot \mathrm{m}^{-3}\right)$ & 0.16 \\
Saturation Pressure $(\mathrm{Pa})$ & 2567 \\
Liquid dynamic viscosity $(\mathrm{Pa} \cdot \mathrm{s})$ & $8.36 \mathrm{e}-4$ \\
Vapor dynamic viscosity $(\mathrm{Pa} \cdot \mathrm{s})$ & $5.44 \mathrm{e}-6$ \\
Number of cells & 20,000 \\
Simulation geometry type & 5 degree wedge \\
$y^{+}$ & $\sim 0.5$ \\
$\Delta s$ & $\sim 2.6 \mathrm{e}-7$ \\
Re & $\sim 160,000$ \\
Turbulence model & $\mathrm{k}$-omega, SST \\
\hline
\end{tabular}

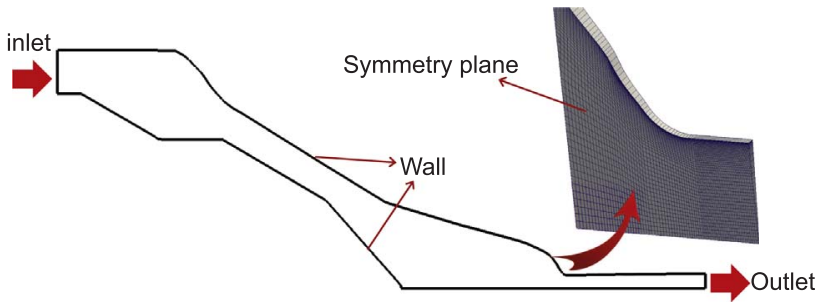

Fig. 4. Simulation geometry and sample of computational mesh for Spray C.

\subsubsection{Effects of inlet/outlet pressure}

The original geometry is an example of an injector suggested by an industrial partner for numerical modeling. Simulations are done in twelve different pressure setups (six different values for inlet pressure and two for different outlet pressure values), and the results are compared with experimental tests. This analysis is used to validate our numerical approach with an original configuration in a series of different working conditions. Additionally, this study is useful for understanding the effect of injection pressure on nozzle performance.

In the experimental setup, following safety considerations, ISO4113 is selected as the working fluid, so in our simulations into the effects of

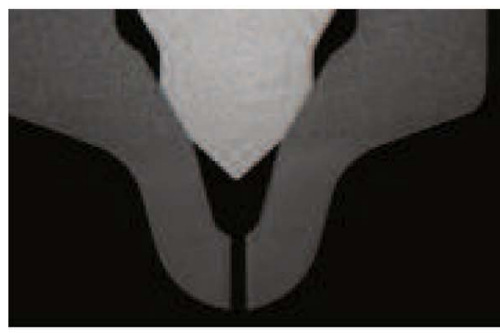

Spray C

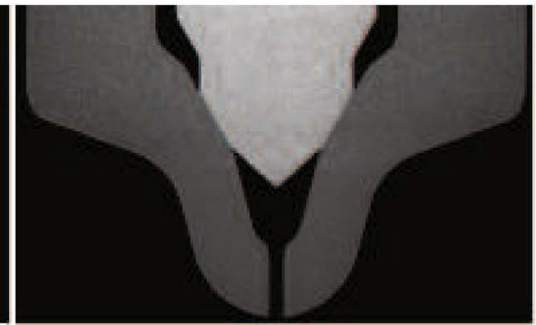

Spray D

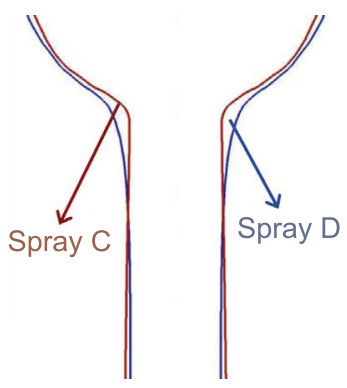

Fig. 3. Tomography photography of Spray C and Spray D cut planes from [21]; comparison of the two geometries is highlighted on the right side. 
Table 4

Case setup and initial conditions for studying the effect of inlet/outlet pressure.

\begin{tabular}{cc}
\hline Nozzle length (micron) & $\sim 1100$ \\
Outlet diameter (micron) & $\sim 205$ \\
$\mathrm{k}$ factor & $\sim 1.5$ \\
Edge rounding (micron) & $\sim 50$ \\
Inlet pressure (bar) & 30,60 \\
Outlet pressure (bar) & ISO 4113 @ $\mathrm{T}=293 \mathrm{~K}$ \\
Fluid type & $5.54 \mathrm{e}-5$ \\
Vapor compressibility $\left(\mathrm{m}^{-2} \cdot \mathrm{s}^{2}\right)$ & $5.39 \mathrm{e}-7$ \\
Liquid compressibility $\left(\mathrm{m}^{-2} \cdot \mathrm{s}^{2}\right)$ & 825 \\
Liquid saturation density $\left(\mathrm{kg} \cdot \mathrm{m}^{-3}\right)$ & 0.16 \\
Vapor density (kg. $\left.\mathrm{m}^{-3}\right)$ & 6 \\
Saturation Pressure $(\mathrm{Pa})$ & $3.74 \mathrm{e}-3$ \\
Liquid dynamic viscosity $(\mathrm{Pa} \cdot \mathrm{s})$ & $5.44 \mathrm{e}-6$ \\
Vapor dynamic viscosity $(\mathrm{Pa} \cdot \mathrm{s})$ & 19,500 \\
Number of cells & 5 degree wedge \\
Simulation geometry type & $\sim 0.7$ \\
$\mathrm{y}+$ & $\sim 4.5 \mathrm{e}-7$ \\
$\Delta s$ & $\sim 23,000$ \\
Re & $\mathrm{k}-\mathrm{omega}, \mathrm{SST}$ \\
\hline Turbulence model &
\end{tabular}

inlet and outlet pressure, the thermophysical properties of ISO4113 by Chorkazewski et al. [27] are applied. The case setup and initial conditions are presented in Table 4. As some information regarding ISO4113 is not available, the values not presented in [27] are assumed according to the similarities between ISO4113 and n-Dodecane.

Fig. 5 shows the nozzle geometry, geometrical parameters, and a sample of the computational grid in the throat. With an assumed axisymmetric shape, a wedge section is used for simulations to reduce the simulation cost.

\subsubsection{Effects of nozzle geometry}

After comparing the numerical results with the experimental outcomes, a brief analysis of the effects of geometry characteristics is performed. With the aim of understanding the role of inlet rounding and nozzle conicity in injector performance, two series of geometries from the original shape are defined. In the first analysis, six cases with different $k$ factors from 0 to 2.5 and the fixed inlet rounding set at 20 microns are modeled. After that, seven cases with different nozzle inlets (r) varying from 1 to 50 microns with a constant $k$ set to 1.5 are analyzed. Fig. 5 shows the schematic for the shape parameters. This part of the work considers the thermophysical properties of n-Dodecane. Table 5 shows the case setup along with the initial conditions for studying the role of hole conicity and edge rounding.

\section{Simulations results: Presentation and discussion}

In this part, the outcomes of the different case studies are presented.

To have an estimation about processing time of this methodology, simulation of Spray C by using a PC with Intel Core i7 Xeon Processor $3.5 \mathrm{GHz}$ technology and $16 \mathrm{~GB}$ RAM, with parallel processing on $6 \mathrm{CPU}$ took around $50 \mathrm{~h}$. For initiating the simulations, boundary conditions as
Table 5

Case setup and initial conditions for studying the effect of nozzle geometry.

\begin{tabular}{|c|c|c|}
\hline Nozzle length (micron) & \multicolumn{2}{|c|}{1100} \\
\hline Outlet diameter (micron) & \multicolumn{2}{|c|}{205} \\
\hline Inlet pressure (bar) & \multicolumn{2}{|c|}{1500} \\
\hline Outlet pressure (bar) & \multicolumn{2}{|c|}{60} \\
\hline Fluid type & \multicolumn{2}{|c|}{ n-Dodecane @ $T=363 \mathrm{~K}$} \\
\hline Number of cells & \multicolumn{2}{|c|}{$\sim 20,000$} \\
\hline Simulation geometry type & \multicolumn{2}{|c|}{5 degree wedge } \\
\hline$y^{+}$ & \multicolumn{2}{|c|}{$\sim 0.7$} \\
\hline$\Delta s$ & \multicolumn{2}{|c|}{$\sim 4.5 \mathrm{e}-7$} \\
\hline $\operatorname{Re}$ & \multicolumn{2}{|c|}{$\sim 140,000$} \\
\hline Turbulence model & \multicolumn{2}{|c|}{ k-omega, SST } \\
\hline Study parameter & Nozzle conicity & Inlet edge \\
\hline$k$ factor & $0,0.5,1.0,1.5,2.0,3.0$ & 1.5 \\
\hline Edge rounding (micron) & 20 & $1,5,10,20,30,40,50$ \\
\hline
\end{tabular}

fuel common rail pressure and combustion chamber pressure are set for initial values in inlet and outlet sector. Also, proper no slip conditions are used for injector wall.

By running the simulation, physical parameters inside the domain will be updated in each time step until reaching the final state. Maximum Courant number and acoustic Courant number are controlled to prevent the divergence. For defining the proper time for end of the simulation, mass conservation is checked by checking the inlet and outlet mass flow rate from two aspects: first due to the difference of the mass flow rate between inlet and outlet sector, and second the change of the values in comparison to the previous time step. For the studies which the cavitation clouds show fluctuations and subsequently flow rate shows fluctuations, simulations are continued until finding a periodic behavior of the fluctuations and satisfaction of the mass conservation in inlet/outlet average mass flow rate. As an example, in Fig. 6, results for mass flow rate in inlet and outlet sector of a simulation for Spray C wedge sector are presented.

\subsection{Results for scaled-up, two dimensional geometry}

Experimental measurements are reported as a function of the outlet mean velocity. Inlet pressures are varied from 2 to 7 bar to obtain outlet mean speeds similar to the experimental results. In the nozzle entrance section, the occurrence of flow separation, local vorticities, and respectively pressure reduction is predictable because of the sharp, solid edge and the sudden change in flow direction. This pressure reduction can reach the saturation pressure and develop a cavitation regime. Fig. 7 shows a flow field inside the nozzle presented for analysis with a 5 -bar inlet pressure at $t=0.05 \mathrm{~s}$.

As reported in Pratama et al. [16] and Tahmasebi et al. [28,29], the cavitation zone in this geometry is not steady, and the results show some fluctuating patterns and large cavitation clouds shedding at an interval on the order of milliseconds. Fig. 8 displays the cavitation inside the studied nozzle for different inlet pressures and consequently distinct mean velocities at the outlet section. The cavitation regime is visualized by illustrating the average vapor ratio over a period of
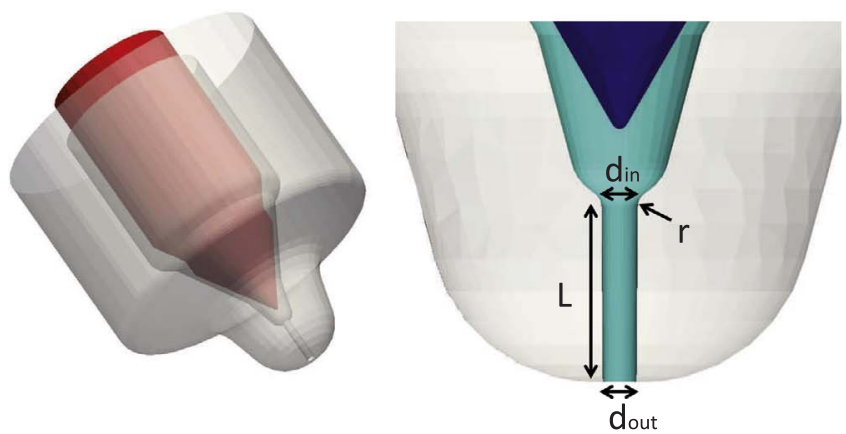

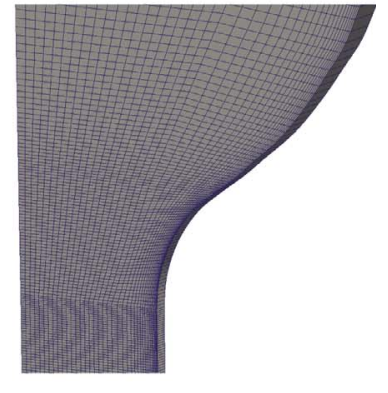

Fig. 5. Schematic of the studied case: the left side shows the injector nozzle and its needle, the center image illustrates the flow path inside the nozzle and its dimensional parameters, while the right side presents a part of the wedge grid in the hole entrance. 


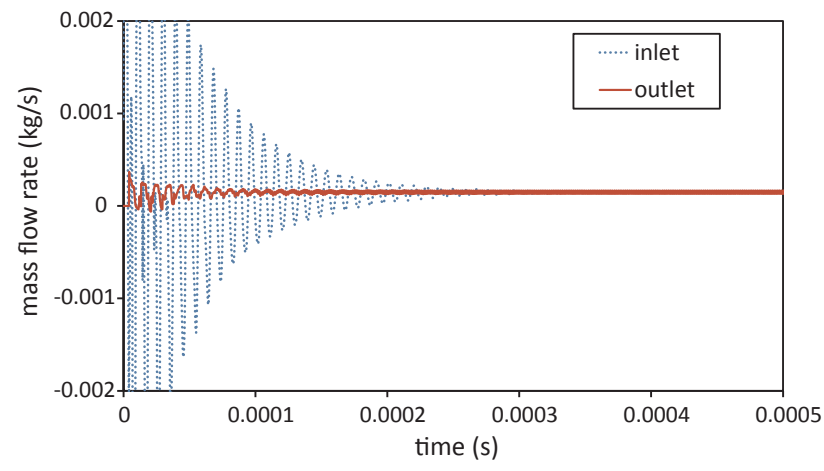

Fig. 6. Comparison of the results for mass flow rate in inlet and outlet sector of Spray C wedge geometry simulation.

$0.005 \mathrm{~s}$ at $t=0.05 \mathrm{~s}$. Fig. 8 shows that increased inlet pressure amplifies the effect of the entrance edge and expands the cavitation area inside the hole. This phenomenon is to be considered in the design and analysis of modern injectors with a tendency to using higher rail pressures.

To find a relation between the amount of cavitation inside the hole and inlet pressure (or outlet velocity), we define the cavitation length ratio as $\left(L_{c} / L_{\text {nozzle }}\right)$ in which $L_{c}$ is the farthest point of the cavitated regime from the inlet. Also, $L_{\text {nozzle }}$ is the total length of the nozzle. To measure this parameter in simulation results, due to the lack of information about resolution of experimental images, $L_{c}$ is measured for the cavitation clouds with a vapor threshold equal to $10 \%(\gamma \geqslant 0.1)$ and $1 \%(\gamma \geqslant 0.01)$. A schematic of the vapor threshold is illustrated on the left side of Fig. 8. In the cases with lower outlet mean velocities, the amount of pressure inside the hole is higher than that of the saturation condition, and accordingly, cavitation does not occur. In cases with higher flow velocity, the effect of the flow rotation in the sharp corner and the injector throat have become dominant. Consequently, the fluid pressure decreases up to the saturation pressure which sets off cavitation forming inside the nozzle. The length of the cavitation regime incloud reaches the outlet section.

According to the presence of the attached, semi-attached, and detached bubbles inside the channel with cavitation, the behavior of the flow shows some fluctuations. These fluctuations are shown with error bars in the experimental measurements of Fig. 9. Given such fluctuating behavior, Fig. 9 indicates that the simulation outcome, especially for those measurements with a $10 \%$ vapor threshold is within the experimental results domain, and our methodology can predict the cavitation regime inside the nozzle with tolerable accuracy. creases in cases with higher mean velocities insofar as the cavitation

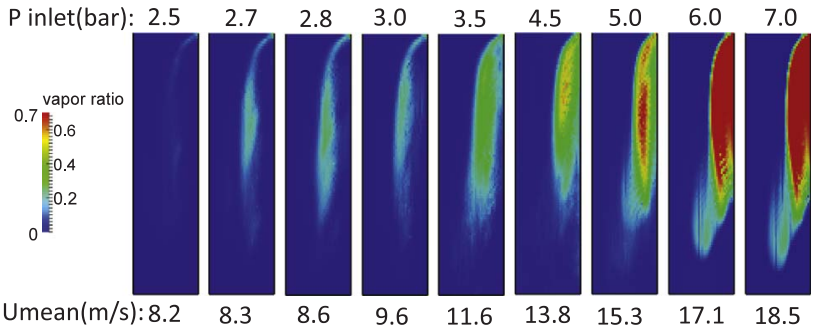

Fig. 8. Cavitation inside the injector nozzle for different inlet pressures.

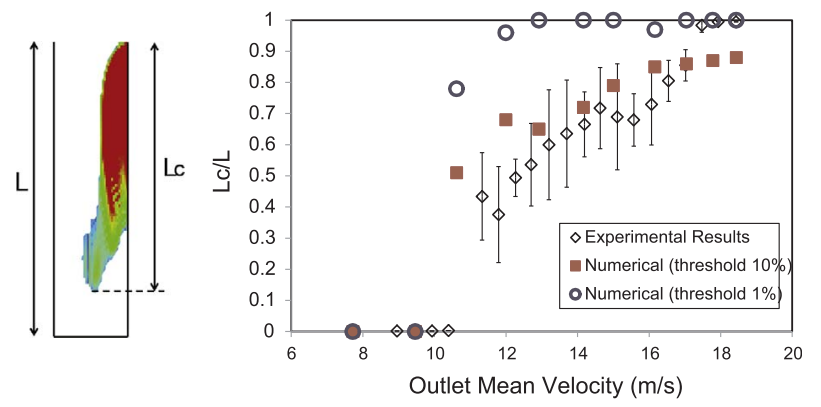

Fig. 9. Cavitation length ratio versus outlet mean velocity, experimental results from [16].

\subsection{Results for Spray $C$ and Spray D injectors}

In this part, we examine the presented method for two different injectors from the ECN database, i.e. Spray C with a cylindrical nozzle and small edge rounding as well as Spray D with $k=1.5$ and a high edge rounding value. As estimated before, an attached cavitation regime appears in the Spray C injector, but there is no cavitation area inside the Spray D injector. The pressure distribution inside the Spray C injector as well as the illustration of the cavitation area are presented in Fig. 10.

Unlike the Spray C injector, because of the shape conicity and also the higher edge rounding, the pressure field inside the nozzle of Spray D follows the geometry change and remains greater than the fuels saturation pressure. Fig. 11 shows that, depending on the presence of the sharper entrance edge as well as the cylindrical hole in the Spray C injector, the pressure across the axis moves toward the saturation pressure of the fuel during working conditions, and cavitation occurs next to the wall behind the nozzle entrance. This attached cavitation cloud continues across the nozzle wall, and flow detachment at the hole entrance is maintained until close to the injector outlet in which the pressure is recovered and increased. The effect of serious change in the pressure field of the Spray C injector throat is apparent on its velocity
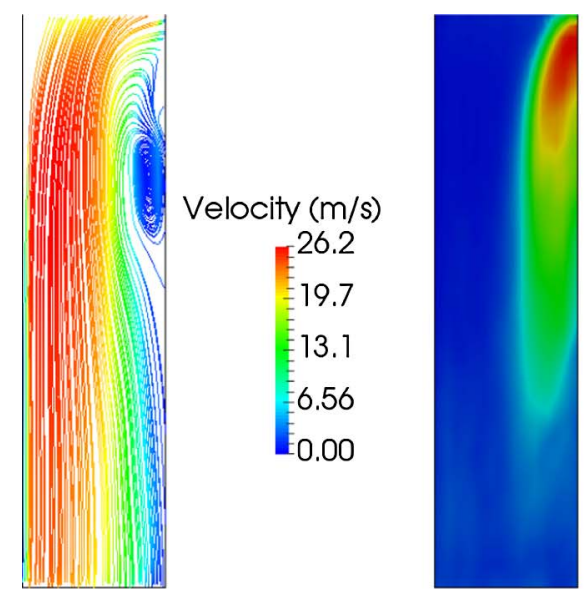

Vapor volumetric ratio

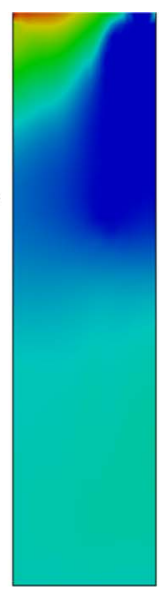

Fig. 7. Flow streamlines, vapor ratio, and pressure distribution inside the nozzle for $P_{i n}=5 \mathrm{bar}$ @ $t=0.05 \mathrm{~s}$.

Pressure (Pa)

0.655
$=0.491$
$=0.328$
$=0.164$
$=0.00$

273361

$=183657$

Е3951.9

4247.05
363066 


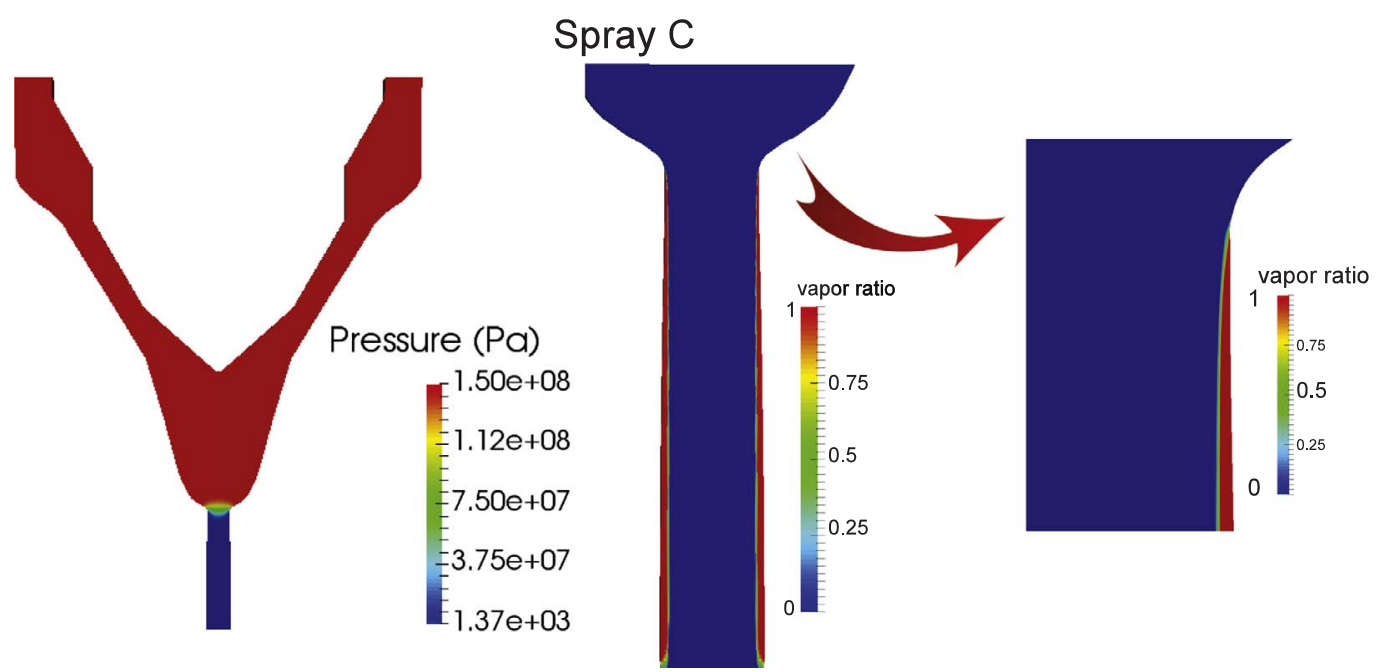

Fig. 10. Simulation results for Spray C geometry: pressure field in injector cross section and distribution of cavitation next to the nozzle wall.

field, as presented in the upper right corner of Fig. 11.

Furthermore, Table 6 compares the results of this study with the experimental measurements by Payri et al. [30]. The discharge coefficient is defined as:

$C_{d}=\frac{\dot{m}}{A_{0} \sqrt{2 \rho d p}}$

in which we use nozzle outlet area, fuel liquid density, inlet/outlet pressure difference and mass flow rate to calculate the discharge coefficient. As per the results in Table 6, the numerical mass flow rate in the Spray C injector is higher than its experimental counterpart, while in Spray D, the numerical mass flow rate is lower than test results. The same behavior was reported by different numerical studies from other contributors in [21]. This disagreement may be associated with the ECN-recommended geometry akin to neglecting surface roughness, asymmetric geometry, and manufacturing tolerances. Improving the assumptions and defining additional tests are two aspects being pursued by ECN contributors.

\subsubsection{Effects of inlet/outlet pressure}

Concerning the effect of the pressure difference on the injector performance, a series of rail pressures varying from 800 to 1800 bar and two chamber pressures, i.e. 30 and $60 \mathrm{bar}$, are used for experimental

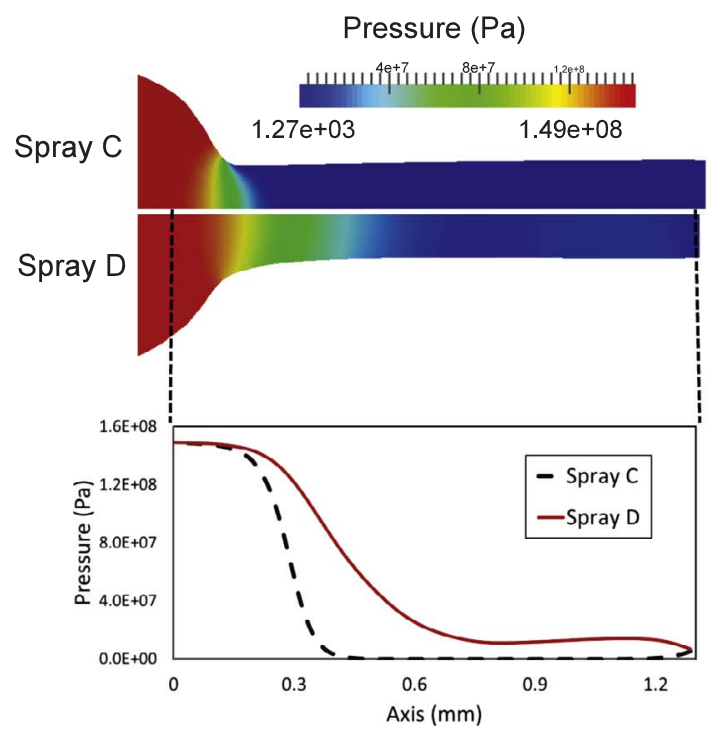

Table 6

Comparison of simulation results for Spray C and D injectors and experimental measurements from ECN database.

\begin{tabular}{cccccc}
\hline Geometry & \multicolumn{2}{c}{ Spray C injector } & & \multicolumn{2}{c}{ Spray D injector } \\
\cline { 2 - 3 } \cline { 5 - 6 } Parameter & $\begin{array}{c}\text { Injection rate } \\
(\mathrm{gr} / \mathrm{s})\end{array}$ & $\begin{array}{c}\text { Discharge } \\
\text { coefficient } \\
\left(C_{d}\right)\end{array}$ & & $\begin{array}{c}\text { Injection rate } \\
(\mathrm{gr} / \mathrm{s})\end{array}$ & $\begin{array}{c}\text { Discharge } \\
\text { coefficient } \\
\left(C_{d}\right)\end{array}$ \\
\hline $\begin{array}{c}\text { Experimental } \\
\text { study } \\
\text { Numerical } \\
\text { results }\end{array}$ & $10.07 \pm 0.11$ & 0.66 & & $11.72 \pm 0.15$ & 0.97 \\
\hline
\end{tabular}

tests. Also, as explained before, in these tests and their numerical simulations, ISO4113 is used as the working fluid.

According to the severe physical conditions of the experimental trials, there are some deviations in the test measurements, specifically in such cases with higher rail pressures. For numerical studies, the mean value of the experimental pressure is used as the inlet pressure, and simulations are undertaken for the geometry with a fully opened injector needle. Fig. 12 shows a sample of experimental measurements for a test with 1600 bar nominal rail pressure and 60 bar chamber

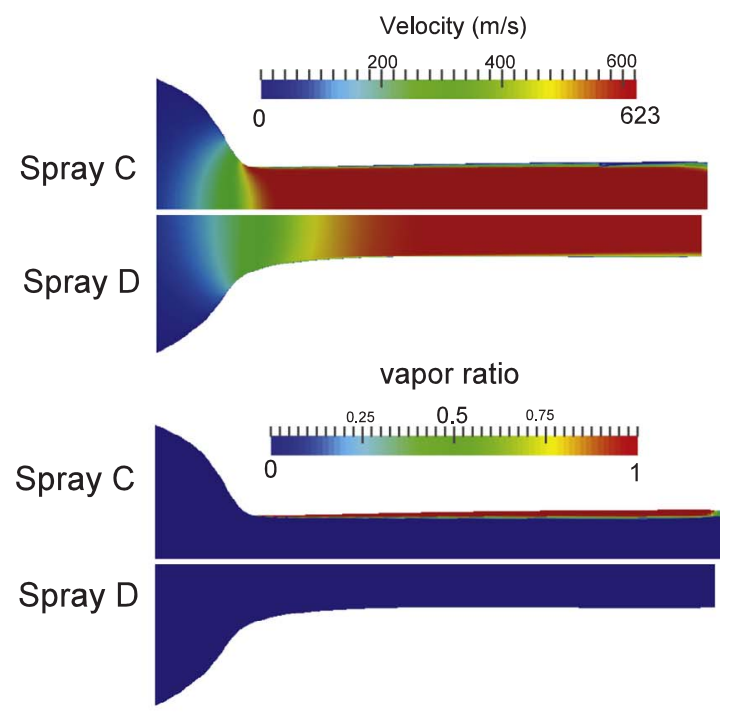

Fig. 11. Comparison of results for Spray C and Spray D injectors. 

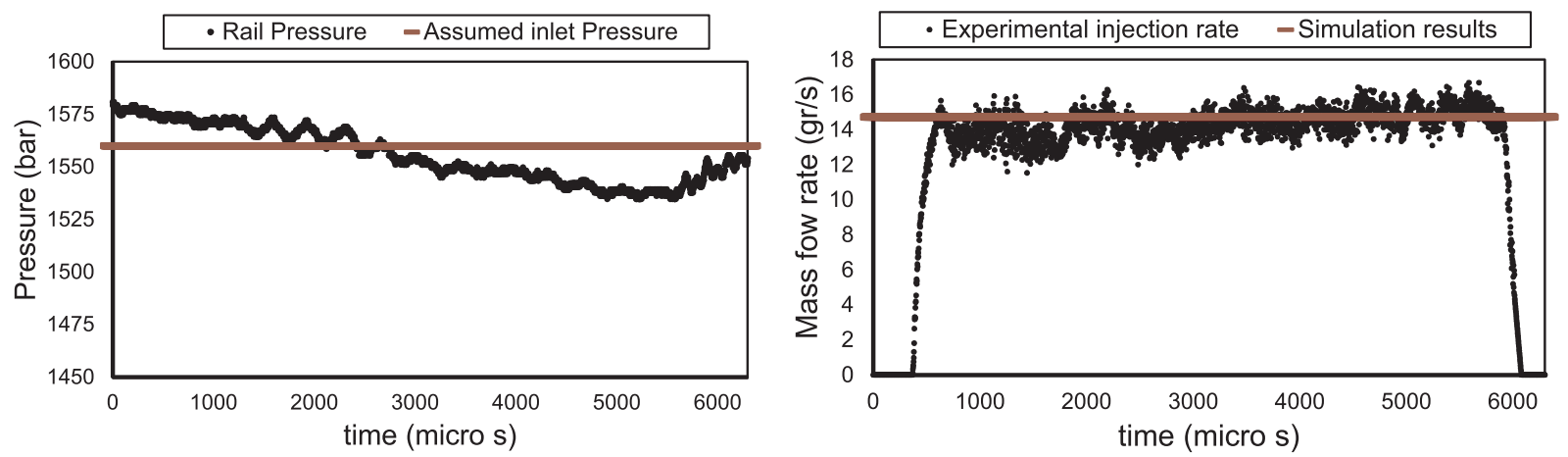

Fig. 12. Rail pressure and injection rate for analysis with 1600 bar nominal rail pressure and 60 bar chamber pressure.

pressure. The rail pressure mean value appears as a constant value on the left hand of the figure while the simulation results for the injection rate appear as a constant value on the right side of the graph.

According to the proper geometry of this injector which has been optimized to suppress cavitation through its high edge rounding and conical nozzle shape, none of the studies show a cavitation regime inside the hole. Fig. 13 presents the results for the pressure and velocity domains across the form for a case with 1600 bar nominal rail pressure and 60 bar chamber pressure at $t=0.002 \mathrm{~s}$. The pressure field shows that the amount of pressure in the nozzle is much higher than the saturation pressure; hence this case is suitable to suppress phase changing in the studied pressure domain.

Fig. 14 shows the results for the injection rate and the discharge factor in different cases. The horizontal axis shows the pressure difference between the inlet and outlet of the injector. Averaging measurements calculate experimental values in a fully-opened needle regime of the injector. As shown in Fig. 14, the injection rate correlates to the pressure difference to the power of 0.4943 which is close to the Bernoulli theorem inside the injector. Furthermore, the discharge coefficient is almost steady within the studied pressure domain. This behavior was expected theoretically along with that of cavitation-free flow. Subsequently, the numerical results show proper conformity with the experimental outcomes, verifying our numerical method in an industrial geometry under real working conditions.

\subsection{Effects of nozzle geometry}

In the previous parts, the validity of the methodology was examined with different geometries and flow conditions. The role of geometry was specified in the Spray C and Spray D analysis. Now to emphasize the role of nozzle shape on the injector performance, two series of investigations are defined by using the industrial model as a baseline.

The effect of the nozzle inlet edge on inflow behavior is studied by changing the inlet edge rounding, from 1 up to 50 microns without changing any other parameters. Results show that the inlet roundings effect on the mass flow rate and also the formation of cavitation inside
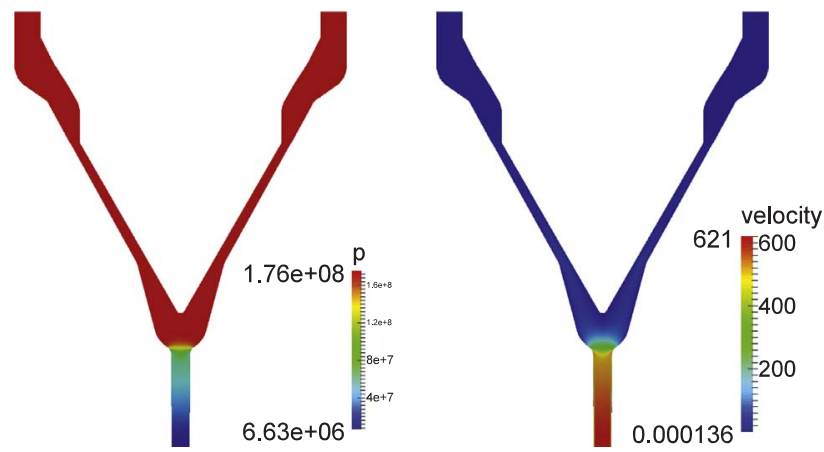

Fig. 13. Simulation results for $P_{\text {inlet }}=1560$ bar and $P_{\text {outlet }}=60$ bar $@ t=0.002 \mathrm{~s}$. the hole is significant. A pressure profile along the axis for different tests is drawn on the left side of Fig. 15. In the cases with low edge rounding ( $r \leqslant 20$ micron), the pressure in the hole inlet drops at a dramatic slope, soon reaching the saturation pressure value which generates a distributed cavitation regime across the nozzle wall. In such conditions, an attached cavitation zone near the solid wall reduces the liquid path section. Such a reduction of the liquid path area decreases the injector mass flow rate and its discharge coefficient. Close to the outlet section, due to the effect of outlet pressure, flow pressure is recovered, and the cavitation zone disappears. However, for the cases with a smoother edge ( $r>30$ microns), the slope of the pressure drop across the axis is more continuous, and the flow shows conformity with the geometry.

Likewise, the effect of the conicity factor is investigated by defining six geometries with different $k$ factors varying from 0.0 up to 3.0 by changing the inlet diameter and keeping other parameters unchanged. As illustrated on the right side of Fig. 15, for conical factors less than or equal to 1.5 , distributed cavitation regimes appeared.

In Fig. 16, the effect of the inlet edge on the injector discharge coefficient is presented in the left graph. A notable change in the slope happening around $r=20$ microns is because of the role of the cavitation regime in the nozzles effective flow area. On the right hand, the effect of the injector conical factor on the nozzle discharge factor is presented. Similarly, a notable change in the slope happens around $k=1.5$ because of the cavitation regime disappearing when $k>1.5$.

\subsection{Results for fluid turbulence characteristics}

One of the dominant mechanisms in the primary breakup of diesel sprays is turbulence-induced disintegration which is described in detail by Schmidt and Corradini [6] as well as Baumgarten [2]. Wu and Faeth [31] found that if the radial turbulent velocity fluctuations inside the nozzle become strong enough, turbulent eddies can overcome the surface tension and induce the jet to form primary drops.

Moreover, according to Schmidt and Corradini [6] and Baumgarten [2], two other possible mechanisms for the primary breakup - the interaction of the surface waves with aerodynamic forces and relaxation of the velocity profile - are strongly influenced by emerging flow turbulence.

Tamaki et al. [32] showed that in internal flows with cavitation, bubbles implode while leaving the nozzle because of the high ambient pressure inside the cylinder. Implosions of cavitation bubbles inside the holes increase the turbulence level and thus also intensify the spray disintegration. Hence, two fundamental breakup mechanisms in highpressure full cone jets are turbulence and cavitation. Results for turbulence dissipation of energy (TDE) and turbulence kinetic energy (TKE) in different pressure setups for industrial geometry are presented in Fig. 17. As described earlier, in this case, there was no sensible cavitation inside the hole, and because of that, the linear growth in TDE and TKE is predictable due to the increased flow velocity in simulations 

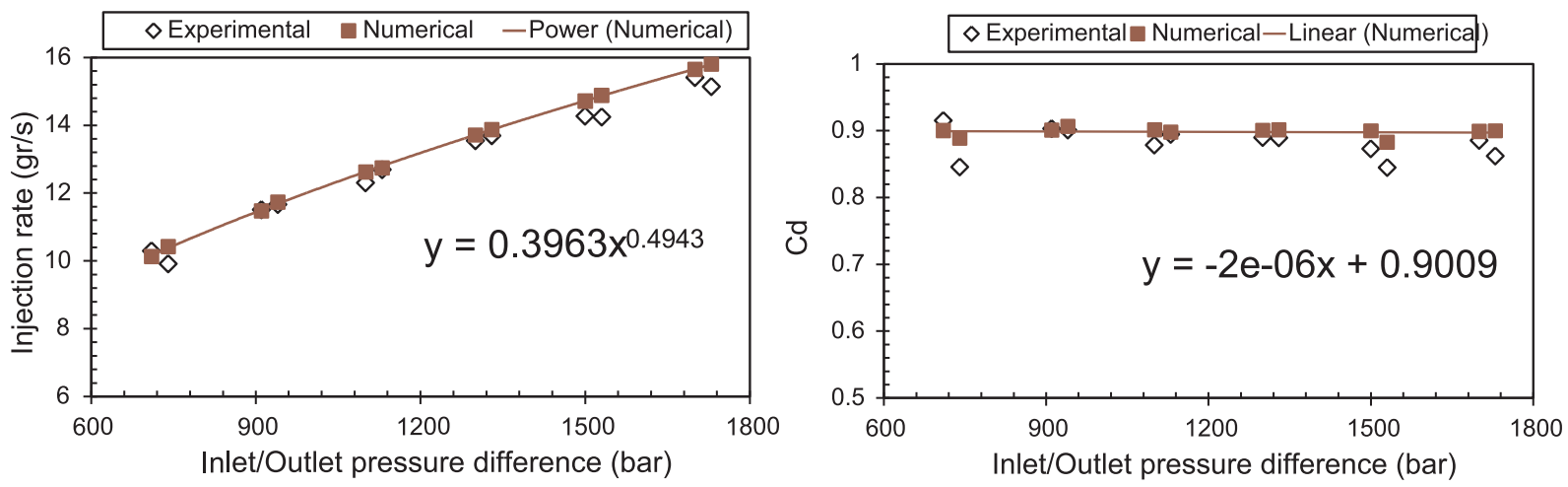

Fig. 14. Results for the injection rate and discharge coefficient in different pressure setup.
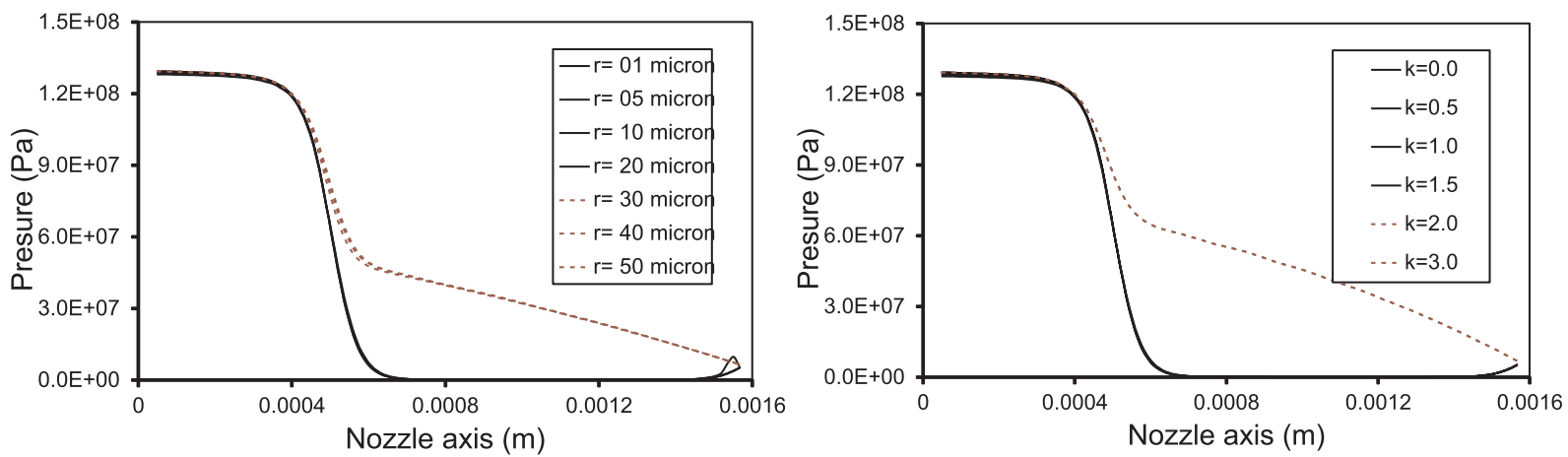

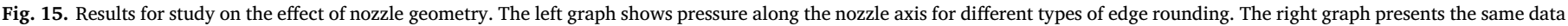
for different $\mathrm{k}$ factors.

with higher pressure differences.

Results for TDE and TKE for different nozzle edge radius and different nozzle conical factor are illustrated in Fig. 18. As presented on the left side, in geometries with lower edge rounding, because of cavitation forming as well as a strong rotation of the flow in the hole entrance, TDE and TKE are significantly high.

In geometries with edge rounding greater than 20 microns with no cavitation inside the nozzle, the gradients of these graphs are smoother. Also, the study of the $k$ factors effect shows similar behavior in cases with lower conicity which are subject to cavitation. As shown on the right side of Fig. 18, for geometries with conicity factors higher than 1.5 , turbulence properties show a small variation with an increase of the $k$ factor. These results clearly show the turbulence level reduction related to the nozzle shape shift from cylindrical to conical as well as switching from the sharp entrance edge to the rounded one.

The availability of the turbulence properties at the nozzle outlet will help us initiate turbulence-induced breakup models to complete the assessment.

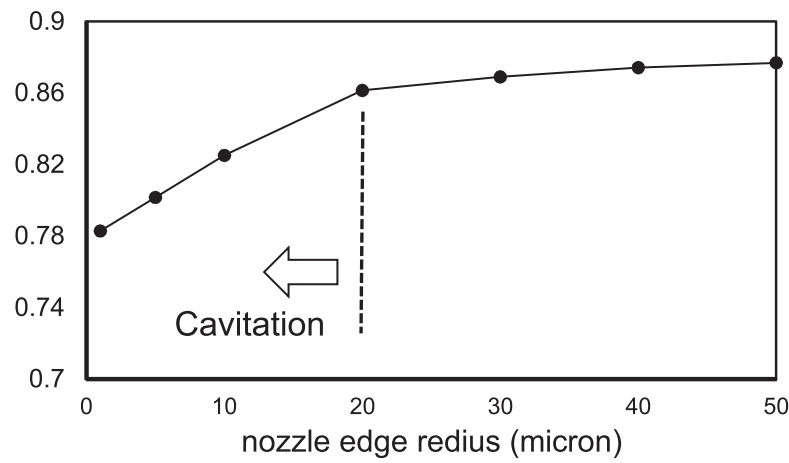

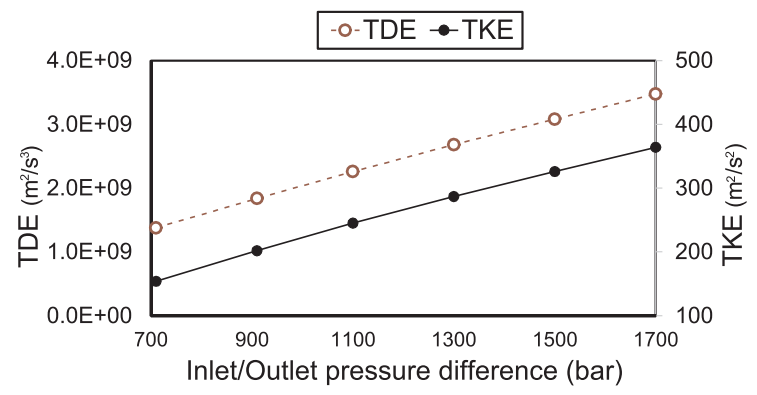

Fig. 17. Average TDE and TKE values at the nozzle outlet versus the inlet/outlet pressure difference.

\section{Conclusion}

Although the numerical methodology applied in this study has been extensively validated in the past, an assessment of the presented

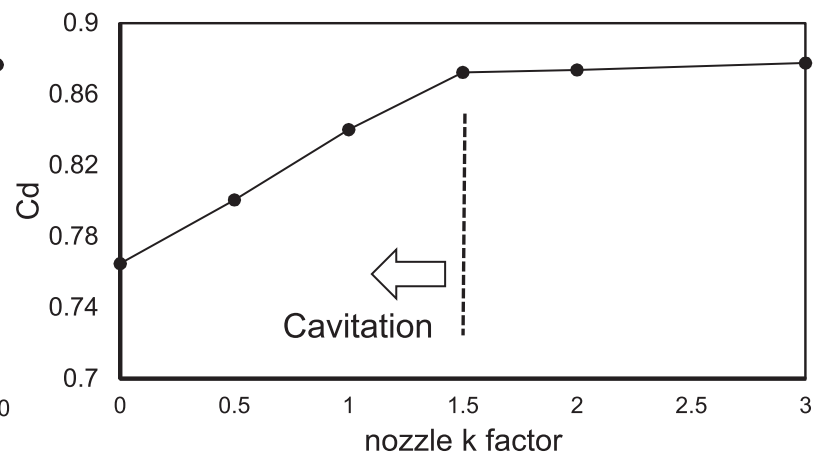

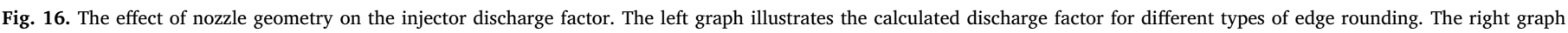
displays the same data for different nozzle $\mathrm{k}$ factors. 

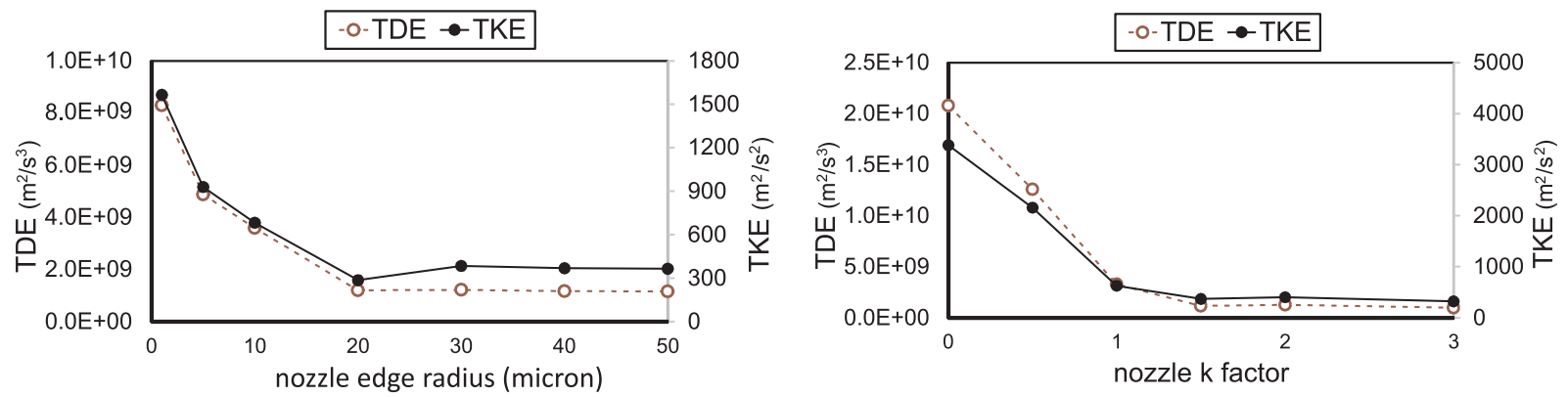

Fig. 18. Average TDE and TKE values at the nozzle outlet section for different types of nozzle edge rounding and nozzle conicity.

methods validity in different studies indicates that the current HEM method provides relatively fast and reliable results for simulating flow behavior under realistic geometries and working conditions. Investigations on the effects of nozzle geometry show that the effect of conicity on the pressure field and the development of cavitation is dominant. Moreover, entrance edge rounding has a significant role in suppressing cavitation inside the tube. The effects of these two parameters are specified by checking the function of the nozzle edge radius and the conical factor on the injector discharge factor and finding critical values for these parameters in the studied geometries. Likewise, the effect of inlet pressure and hole geometry on turbulence characteristics of the emerging flow is analyzed.

In future works, these results may be used to couple internal flow simulation with spray simulation to complete the investigation of the influence of nozzle shape and injection pressure on spray characteristics. The outcomes are useful for further research and development processes of this type of injector; besides, this methodology could be applied to other geometries.

\section{References}

[1] Mahr B. Future and potential of diesel injection systems. Thermo-and fluid dynamic processes in diesel engines, vol. 2. Springer; 2004. p. 3-17.

[2] Baumgarten C. Mixture formation in internal combustion engines. Springer Science \& Business Media; 2006.

[3] Morgan R, Banks A, Auld A, Heikal M, et al., The benefits of high injection pressure on future heavy duty engine performance. Tech Rep, SAE technical paper; 2015.

[4] dAmbrosio S, Ferrari A. Effects of pilot injection parameters on low temperature combustion diesel engines equipped with solenoid injectors featuring conventional and rate-shaped main injection. Energy Convers Manage 2016;110:457-68.

[5] Tay KL, Yang W, Zhao F, Yu W, Mohan B. Numerical investigation on the combined effects of varying piston bowl geometries and ramp injection rate-shapes on the combustion characteristics of a kerosene-diesel fueled direct injection compression ignition engine. Energy Convers Manage 2017;136:1-10.

[6] Schmidt DP, Corradini M. The internal flow of diesel fuel injector nozzles: a review. Int J Engine Res 2001;2(1):1-22.

[7] Desantes J, Payri R, Salvador F, De la Morena J. Influence of cavitation phenomenon on primary break-up and spray behavior at stationary conditions. Fuel 2010;89(10):3033-41.

[8] Salvador F, Gimeno J, Carreres M, Crialesi-Esposito M. Fuel temperature influence on the performance of a last generation common-rail diesel ballistic injector. Part I: Experimental mass flow rate measurements and discussion. Energy Convers Manage 2016;114:364-75.

[9] Payri R, Salvador F, Carreres M, De la Morena J. Fuel temperature influence on the performance of a last generation common-rail diesel ballistic injector. Part II: 1d model development, validation and analysis. Energy Convers Manage 2016;114:376-91.

[10] Hulkkonen T, Sarjovaara T, Kaario O, Hamalainen I, Larmi M. Experimental study of conical diesel nozzle orifice geometry. Atomization Sprays 2015;25.

[11] Salvador F, Romero J-V, Roselló M-D, Martínez-López J. Validation of a code for modeling cavitation phenomena in diesel injector nozzles. Mathe Comput Modell 2010;52(7):1123-32.

[12] Salvador F, Martínez-López J, Caballer M, De Alfonso C. Study of the influence of the needle lift on the internal flow and cavitation phenomenon in diesel injector nozzles by CFD using RANS methods. Energy Convers Manage 2013;66:246-56.

[13] Salvador F, Carreres M, Jaramillo D, Martínez-López J. Comparison of microsac and VCO diesel injector nozzles in terms of internal nozzle flow characteristics. Energy Convers Manage 2015;103:284-99.

[14] Wang C, Li G-X, Sun Z-Y, Wang L, Sun S-P, Gu J-J, et al. Effects of structure parameters on flow and cavitation characteristics within control valve of fuel in jector for modern diesel engine. Energy Convers Manage 2016;124:104-15.

[15] Winklhofer E, Kelz E, Morozov A. Basic flow processes in high pressure fuel injec tion equipment. In: Proceedings of the 9th International conference on liquid atomization and spray systems, ICLASS-2003, Sorento, Italy. ICLASS, vol. 93; 2003.

[16] Pratama RH, Sou A, Wada Y, Yohohata H. Cavitation in mini-sac nozzle and injected liquid jet. In: THIESEL 2014 Conference on thermo and fluid dynamic processes in direct injection engines. Valencia, Spain, 2014.

[17] Battistoni M, Duke DJ, Swantek AB, Tilocco FZ, Powell CF, Som S. Effects of noncondensable gas on cavitating nozzles. Atomization Sprays 2015;25(6).

[18] Bicer B, Sou A. Numerical models for simulation of cavitation in diesel injector nozzles. Atomization Sprays 2015;25(12).

[19] Brusiani F, Bianchi GM, Falfari S, Onorati A, Lucchini T, Di Gioia R. Influence of cylindrical, $\mathrm{k}$, and ks diesel nozzle shape on the injector internal flow field and on the emerging spray characteristics. Tech Rep, SAE technical paper; 2014.

[20] Jasak H, Jemcov A, Tukovic Z, et al. Openfoam: A c + + library for complex physics simulations, in: International workshop on coupled methods in numerical dynamics, vol. 1000, IUC Dubrovnik, Croatia; 2007. p. 1-20.

[21] ECN4, Engine combustion network, 4th workshop. URL < http://www.sandia.gov/ ecn/workshop/ECN4/ECN4.php >; 2015.

[22] Salvador F, De la Morena J, Martínez-López J, Jaramillo D. Assessment of compressibility effects on internal nozzle flow in diesel injectors at very high injection pressures. Energy Convers Manage 2017;132:221-30.

[23] Jasak H. Error analysis and estimation for the finite volume method with applications to fluid flows, Ph.D. thesis, Imperial College London (University of London); 1996.

[24] Versteeg HK, Malalasekera W. An introduction to computational fluid dynamics: the finite volume method. Pearson Education; 2007.

[25] Menter F. Influence of freestream values on k-omega turbulence model predictions. AIAA J 1992;30(6):1657-9.

[26] NIST, Thermophysical properties of fluid systems. URL < http://webbook.nist.gov/ chemistry/fluid/>; 2017.

[27] Chorkazewski M, Dergal F, Sawaya T, Mokbel I, Grolier J-PE, Jose J. Thermophysical properties of normafluid (iso 4113) over wide pressure and temperature ranges. Fuel 2013;105:440-50.

[28] Tahmasebi E, Lucchini T, DErrico G, Onorati A. Numerical simulation of diesel injector internal flow field. Energy Procedia 2015;82:51-8.

[29] Tahmasebi E. Simulation of internal flow in fuel injection process Ph.D. thesis Italy: Politecnico di Milano; 2017.

[30] Payri R, Gimeno J, Cuisano J, Arco J. Hydraulic characterization of diesel engine single-hole injectors. Fuel 2016;180:357-66.

[31] Wu P-K, Faeth G. Onset and end of drop formation along the surface of turbulent liquid jets in still gases. Phys Fluids (1994-present) 1995;7(11):2915-7.

[32] Tamaki N, Shimizu M, Hiroyasu H. Enhanced atomization of a liquid jet by cavitation in a nozzle hole. In: Proc 8th international conference on liquid atomization and spray systems, ICLASS-2000,(2000-7), CD-R; 2000. 